\title{
Conformational study of isolated pindolol by HF, DFT and MP2 calculations
}

\author{
Sandra C.C. Nunes, A.J. Lopes Jesus, Mário Túlio S. Rosado, M. Ermelinda S. Eusébio * \\ Department of Chemistry, University of Coimbra, 3004-535, Coimbra, Portugal
}

Received 26 July 2006; accepted 28 November 2006

Available online 5 December 2006

\begin{abstract}
In the present work a conformational analysis of pindolol, a beta-blocker, is performed using several computational methods, including HF, DFT (B3LYP) and MP2. The relative electronic energies as well as the relevant dihedral angles of the significant conformer geometries are reported.

At the HF and DFT levels the most stable conformers of pindolol are characterized by an extended backbone structure, minimizing the steric repulsions between the indole ring and the side chain. The two backbone dihedrals, defining the position of the ring relatively to the side chain, are found to be particularly important. The lower energy structures obtained by HF and DFT also contribute significantly to the MP2 conformational population. This last method increases the stability of some conformers presenting a more folded backbone.

Most conformers exhibit hydrogen bonding. This feature, although not being the dominant factor in energetic terms, appears to be of foremost importance to define the geometry of the molecule. Four intramolecular hydrogen bonds established between the polar groups were identified by the structural geometric parameters. These involved the hydroxyl and amine functional groups and were identified and characterized by the frequency shift in their stretching vibration modes.
\end{abstract}

(c) 2006 Elsevier B.V. All rights reserved.

Keywords: Pindolol; Beta-blocker; Conformational analysis; Hydrogen bonding; HF; DFT; MP2

\section{Introduction}

The main goal of the present paper is to investigate the structure of the pindolol isolated molecule. This compound, belonging to a series of drugs commonly known as beta-blockers, is widely used in medical practice in blood pressure control and in the treatment of heart diseases [13].

In a previous work performed in our research group using calorimetric methods (differential scanning calorimetry and polarized light thermomicroscopy) three polymorphic forms of pindolol were identified by crystallization of the melt and two different arrangements were found to exist in the solid before being melted [4]. In either case the forms were found to have close energy, possibly due

\footnotetext{
* Corresponding author. Tel.: +351239854450; fax: +351239827703 .

E-mail address: quierme@ci.uc.pt (M. Ermelinda S. Eusébio).
}

to a similar H-bond network differing among them only in the conformation of the non-polar parts. The possible existence of different conformations identified in the condensed states makes the study of the isolate molecule a worth to note issue.

Two of the most relevant sources to get a deep insight into the structure of any compound are the data supplied by X-ray for the crystalline state and the computational modeling of the gas state. In the case of pindolol the crystalline structure of a solid obtained from ethanol and methanol solutions is known [5,6]. The investigation of the isolated molecule structure, subject of the present paper, fulfills the second goal. The study of the conformational space of the isolated molecule can help to understand the possible conformations of the compound in the condensed states, besides supplying data on the gas state of the compound, which is normally the reference state for the thermodynamic properties. 




Fig. 1. Molecular structure of pindolol (1-(1H-Indol-4-yloxyl)-3-isopropylamino-propan-2-ol) with atom numbering scheme.

Despite the currently available computational resources, the study of molecules with the size and flexibility of those of pindolol (see Fig. 1) at a high level of theory is a hard undertaking. To reach this goal, a study of the lower energy conformers of pindolol in the gas state is performed in the present work. In order to choose the relevant conformations to investigate, among the great number of possible candidates, a conformational search method using less expensive theoretical approximations (molecular mechanics and semi-empirical calculations) is employed to generate an initial set of relevant structures of the isolated molecule. These structures are further investigated by means of HF and high-level DFT (B3LYP) and MP2 theoretical calculations, allowing the determination and comparison of the energy of the conformers, as well as the identification of the most important structural features that contribute to their stabilization. A comparison of the results obtained by the different electronic structure methods employed is also included in order to investigate the relevance of both correlation and dispersion effects in the conformers energy.

A discussion on the conformational features of the intramolecular hydrogen bonding is also given based on the geometrical parameters, as well as on the calculated infrared vibrational frequencies of the investigated conformers.

\section{Computational details}

The pindolol molecule has a chiral center giving rise to two enantiomers, $R$ and $S$. As far as the isolated molecules are concerned both enantiomers are conformationally and energetically equivalent. In this work the calculations were only performed on the $S$ enantiomer. This molecule is very flexible, having eight relevant dihedrals, six of them related to the backbone structure and two other with the $\mathrm{OH}$ and $\mathrm{NH}$ groups orientation. Assuming a three-fold rotation for each one of the dihedrals, one can obtain $3^{8}=6561$ possible minima, thus being computationally very expensive to explore all of them by means of high level electronic structure methods. Therefore, a preliminary conformational search method employing less expensive theoretical approaches was used to obtain a reasonable sampling of the most relevant conformations of pindolol.
In this work the conformational search was carried out using semiempirical (AM1) [7] and molecular mechanics (MM) methods, both employing random generation and subsequent full minimization of every internal coordinate. This random generation involved random torsion changes to the single bonds (all excluding those containing the methyl groups), followed by minimization of all internal coordinates either by molecular mechanics or semi-empirical calculations. This cycle of random changes and minimization was repeated many times until a reasonable sampling of low energy structures was obtained and for many starting structures. The molecular mechanics calculations were carried out with the CFF91 force field $[8,9]$ using the Cerius $^{2}$ (version 3.5) molecular modeling package running on an SGI $\mathrm{O}^{2} / \mathrm{RS} 5000$ workstation. The conformational search with the AM1 semi-empirical method was performed using the Hyperchem software [10]. Details of the conformational search methods can be found in the Cerius $^{2}$ and Hyperchem 7.5 manuals.

The generated conformations with relative energies up to $10 \mathrm{~kJ} \mathrm{~mol}^{-1}$ above the global minimum, corresponding to twenty structures obtained from molecular mechanics and seventeen from AM1, were then fully optimized at the Hartree-Fock (HF) level of theory using the $6-31 \mathrm{G}^{*}$ basis set followed by vibrational frequencies calculation at the same level of theory. The absence of imaginary frequencies in each of the resulting conformations was used to confirm that all of them correspond to true minima on the potential energy surface.

Some folded structures initially generated by the semiempirical and MM conformational search methods converged to more extended ones after full optimization at the HF/6-31G ${ }^{*}$ level. The starting structures were characterized by the possible formation of $\mathrm{NH} \cdots \pi$ and $\mathrm{OH} \cdots \pi$ interactions, which have been reported as relevant stabilization factors in the conformational space of other molecular systems similar to pindolol [11-14]. For this reason, it was found important to include these folded structures in the conformational analysis. However, only a few folded conformations (six) were generated by the methods used in the conformational search described above, in an energy range of $c a .25 \mathrm{~kJ} \mathrm{~mol}^{-1}$. In order to further investigate the importance of these kind of structures in the conformational space of pindolol, a new search was performed using the PM3 semiempirical method $[15,16]$. All folded conformations generated by this method, within an energy range of $c a .25 \mathrm{~kJ} \mathrm{~mol}^{-1}$ (ten) were also analyzed.

A total of sixteen folded conformations (identified as $\mathrm{E}_{\mathrm{A}}$ to $\mathrm{E}_{\mathrm{P}}$ ) have been investigated. To maintain the $\mathrm{NH} \cdots \pi$ and $\mathrm{OH} \cdots \pi$ interactions throughout the HF minimization, some internal coordinates had to be frozen. Constraining some backbone torsional dihedrals was found to be inadequate, since it resulted in too high energies, not comparable with those derived by full optimization. The best alternative was to fix the distance between $\mathrm{H}_{15}(\mathrm{NH} \cdots \pi)$ or $\mathrm{H}_{13}$ $(\mathrm{OH} \cdots \pi)$ and the closest aromatic carbon atom and allowing all the remaining coordinates to relax. The frozen 
distance values were those obtained from semiempirical and MM minimizations (values between 2.2 and $3.1 \AA$, see Supplementary material).

Additional single-point calculations on the HF fully and partially optimized structures were carried out by DFT $[17,18]$, using the B3LYP functional [19-21] and MP2 $[22,23]$, both employing the $6-311++\mathrm{G}^{* *}$ basis set. All the electronic structure calculations were performed using the Gaussian 98 program package [24].

\section{Results and discussion}

\subsection{Structural features of the low energy conformers}

Table 1 displays the conformations obtained by the methodology described above: the thirty most stable conformers fully optimized by $\mathrm{HF}$ and the sixteen folded conformations partially optimized $\left(\mathrm{E}_{\mathrm{A}}\right.$ to $\left.\mathrm{E}_{\mathrm{P}}\right)$. All of them are identified by six letters according to the configuration of the backbone dihedrals. The letters used are $\mathrm{T}$ (trans), G (gauche clockwise), $\mathrm{G}^{\prime}$ (gauche anticlockwise), corresponding to dihedrals of $180^{\circ},+60^{\circ}$ and $-60^{\circ}$, respectively, with a tolerance of $\pm 60^{\circ}$. Two further dihedrals are required to define the orientation of $\mathrm{O}-\mathrm{H}$ and $\mathrm{N}-\mathrm{H}$ groups, which may play a role in the stabilization energy of the conformers by specific interactions. Fig. 2 displays some conformers of pindolol illustrating the most important features of its structure.

The values of the dihedral angles and relative electronic energies relative to the global minimum (at the HF, DFT and MP2 levels) are given in Table 1. The conformers were ordered by their DFT electronic energy. The relative energy values of the starting structures generated from the semiempirical and MM search methods are given as Supplementary material.

From the analysis of the results in Table 1, it can be noted that most of the lower energy structures predicted by HF and DFT have also a significant weight in the conformational distribution at the MP2 level. Moreover, the global minimum on the HF potential energy surface is the third lowest energy conformation $\left(\Delta E \mathrm{ca} .2 .6 \mathrm{~kJ} \mathrm{~mol}^{-1}\right)$ at the MP2 level. Despite this, at the HF and B3LYP levels, the conformations exhibiting more extended backbones seem to be favoured, while at the MP2 level the stabilization of some of the more folded conformations occurs (see for example the geometry of $\mathrm{E}_{\mathrm{F}}, \mathrm{E}_{8}, \mathrm{E}_{13}$ and $\mathrm{E}_{15}$ ).

Although the molecular structure characterization of pindolol depends on the joint configuration of all dihedrals, $\varphi_{1}$ and $\varphi_{2}$, defining the position of the side chain relatively to the indole group, apparently play a crucial role in the structure of this compound. In fact, for most of the lower energy conformers, the $\varphi_{1}$ dihedral assumes the same trans configuration at all used levels of theory. This is in agreement with the theoretical and experimental results obtained for the conformational landscape of 2-phenoxyethanol [25], where the planar arrangement of the side chain relative to the ring $\left(\mathrm{CC}_{\mathrm{arom}}-\mathrm{OC} \approx 0^{\circ}\right.$ or $\left.180^{\circ}\right)$ was found to be more stable than the perpendicular one $\left(\mathrm{CC}_{\text {arom }}-\mathrm{OC} \approx 90^{\circ}\right)$.

In the case of the $\varphi_{2}$ dihedral, the variability is slightly more dependent on the employed method. Hence, at the $\mathrm{HF}$ and DFT levels the most stable conformers tend to adopt predominantly a trans $\varphi_{2}$ configuration whereas at the MP2 level some of the most stable conformers exhibit an "open" $\mathrm{G}$ or $\mathrm{G}^{\prime} \varphi_{2}$ arrangement, with values close to $100^{\circ}$ (see for example $\mathrm{E}_{\mathrm{F}}, \mathrm{E}_{13}$ and $\mathrm{E}_{15}$ conformations). Another relevant dihedral is $\varphi_{5}$, which tends to adopt preferentially a trans configuration at all levels of theory, corresponding to the minimum repulsive interaction between the isopropyl group and the remaining side chain. Also, the repulsive interaction between the terminal methyl and $\mathrm{C}_{14}$ methylene group imposes a $\mathrm{G}$ or $\mathrm{G}^{\prime}$ configuration for $\varphi_{6}$.

For the most stable conformers of pindolol, the remaining dihedrals take different configurations without moving $\varphi_{1}, \varphi_{2}, \varphi_{5}$ and $\varphi_{6}$ from the preferred orientations defined above.

A detailed analysis of Table 1 and Fig. 2 shows that at the $\mathrm{HF} / 6-31 \mathrm{G}^{*}$ and $\mathrm{B} 3 \mathrm{LYP} / 6-311++\mathrm{G}^{* *}$ levels of theory the lower energy conformations have one or both of the middle dihedral angles in a trans configuration leading to a extended side chain in which the indole ring is moved away from the remaining backbone. Besides the reduction of the repulsion interactions between the side chain and the indole ring the formation of $\mathrm{O}-\mathrm{H} \cdots \mathrm{NH}, \mathrm{O}-\mathrm{H} \cdots \mathrm{O}$ and $\mathrm{N}-$ $\mathrm{H} \cdots \mathrm{OH}$ intramolecular hydrogen bonds is another structural feature that should be included to explain the stability of these forms. With only a few exceptions it is worth noticing that the stability order of the conformations given by DFT closely resembles that obtained by HF. Also, the global minimum attained by the HF calculations corresponds to the lowest energy conformation after single point calculations at the DFT level.

Regarding the MP2 single point calculations, some of the folded conformations (with $\varphi_{3}$ and $\varphi_{4}$ in a $\mathrm{G}$ or $\mathrm{G}^{\prime}$ orientation), not predicted as low energy structures at the DFT and HF levels, become very stable. This is the case for $\mathrm{E}_{\mathrm{F}}, \mathrm{E}_{8}, \mathrm{E}_{13}, \mathrm{E}_{15}, \mathrm{E}_{\mathrm{B}}, \mathrm{E}_{\mathrm{D}}$ and $\mathrm{E}_{\mathrm{A}}$. The stabilization of these conformations can be, in some cases, attributed to the formation of intramolecular $\mathrm{H}$-bonds between the $\mathrm{NH}$ group and the ether oxygen $\left(\mathrm{E}_{8}, \mathrm{E}_{13}, \mathrm{E}_{15}, \mathrm{E}_{\mathrm{B}}\right.$ and $\mathrm{E}_{\mathrm{A}}$ ), and also to the long-range dispersion forces between the side chain and the $\pi$ system of the indole ring, including possible $\mathrm{NH} \cdots \pi$ and $\mathrm{OH} \cdots \pi$ interactions (see Fig. 2). This effect has already shown to play an important role in the stabilization of the folded conformers of various molecules with a structure similar to that of pindolol $[11,12,14,26]$.

The differences between DFT and MP2 in predicting the most significant conformations of molecular systems similar to pindolol have been reported by some authors $[14,26]$. It is generally accepted that the commonly used density functionals, such as B3LYP, tend to underestimate dispersion effects which may play a role in the conformational stability of aromatic organic molecules. 
Table 1

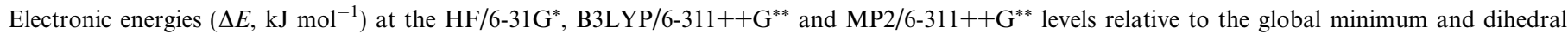

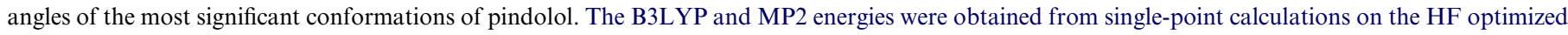
structures $^{\mathrm{a}}$

\begin{tabular}{|c|c|c|c|c|c|c|c|c|c|c|c|c|}
\hline \multirow[t]{2}{*}{ Conf. ${ }^{b}$} & \multirow[t]{2}{*}{ Label } & \multicolumn{3}{|c|}{$\Delta E\left(\mathrm{~kJ} \mathrm{~mol}^{-1}\right)$} & \multirow[t]{2}{*}{$\varphi_{1}$} & \multirow[t]{2}{*}{$\varphi_{2}$} & \multirow[t]{2}{*}{$\varphi_{3}$} & \multirow[t]{2}{*}{$\varphi_{4}$} & \multirow[t]{2}{*}{$\varphi_{5}$} & \multirow[t]{2}{*}{$\varphi_{6}$} & \multirow[t]{2}{*}{$\varphi_{7}$} & \multirow[t]{2}{*}{$\varphi_{8}$} \\
\hline & & $\mathrm{HF}$ & B3LYP & MP2 & & & & & & & & \\
\hline $\mathrm{E}_{1}$ & TTTG $^{\prime}$ TG & 0.00 & 0.00 & 2.59 & 179 & -177 & -180 & -60 & -174 & 47 & -48 & -52 \\
\hline $\mathrm{E}_{2}$ & TTTTTG' & 3.27 & 1.13 & 6.63 & 180 & -177 & 179 & 177 & 172 & -48 & -55 & 49 \\
\hline $\mathrm{E}_{3}$ & $\mathrm{TTG}^{\prime} \mathrm{TTG}^{\prime}$ & 0.35 & 1.31 & 5.55 & 180 & -180 & -64 & -175 & 162 & -56 & 162 & -73 \\
\hline $\mathrm{E}_{4}$ & $\mathrm{TTG}^{\prime} \mathrm{TTG}$ & 1.77 & 1.84 & 5.25 & 180 & -180 & -65 & -176 & 169 & 42 & 162 & -69 \\
\hline $\mathrm{E}_{5}$ & $\mathrm{TTG}^{\prime} \mathrm{G}^{\prime} \mathrm{TG}$ & 2.14 & 2.43 & 3.35 & 180 & -179 & -58 & -66 & -156 & 56 & 86 & 80 \\
\hline $\mathrm{E}_{6}$ & $\mathrm{TTTG}^{\prime} \mathrm{TG}^{\prime}$ & 1.29 & 2.52 & 6.63 & 179 & -177 & -179 & -58 & 176 & -53 & -48 & -58 \\
\hline $\mathrm{E}_{7}$ & $\mathrm{TTG}^{\prime} \mathrm{G}^{\prime} \mathrm{TG}^{\prime}$ & 3.79 & 3.05 & 3.10 & 180 & -179 & -57 & -65 & -159 & -40 & 86 & 78 \\
\hline $\mathrm{E}_{8}$ & $\mathrm{TTGG}^{\prime} \mathrm{TG}$ & 4.75 & 3.29 & 0.27 & -173 & 176 & 60 & -78 & -162 & 55 & 90 & 71 \\
\hline $\mathrm{E}_{9}$ & TTTG TG $^{\prime}$ & 5.49 & 5.74 & 9.63 & 180 & -178 & 178 & 63 & -177 & -44 & -49 & 61 \\
\hline $\mathrm{E}_{10}$ & TTG TTG $^{\prime}$ & 8.12 & 5.92 & 9.41 & -178 & 178 & 53 & -178 & 162 & -55 & 163 & -73 \\
\hline $\mathrm{E}_{11}$ & TTTG TG & 4.93 & 6.11 & 11.63 & 180 & -178 & 178 & 64 & -167 & 56 & -49 & 68 \\
\hline $\mathrm{E}_{12}$ & $\mathrm{TG}^{\prime} \mathrm{G}^{\prime} \mathrm{TTG}^{\prime}$ & 6.89 & 6.43 & 7.78 & -177 & -86 & -63 & -175 & 163 & -56 & 162 & -72 \\
\hline $\mathrm{E}_{13}$ & $\mathrm{TGGG}^{\prime} \mathrm{TG}$ & 8.56 & 7.89 & 3.49 & 146 & 111 & 54 & -80 & -162 & 55 & 96 & 70 \\
\hline $\mathrm{E}_{14}$ & TTGGTG & 7.60 & 8.29 & 10.61 & -180 & 178 & 68 & 66 & -162 & 56 & 47 & 73 \\
\hline $\mathrm{E}_{15}$ & $\mathrm{TGGG}^{\prime} \mathrm{TG}^{\prime}$ & 9.93 & 8.54 & 3.74 & 145 & 111 & 54 & -79 & -168 & -42 & 96 & 68 \\
\hline $\mathrm{E}_{16}$ & $\mathrm{TTG}^{\prime} \mathrm{G}^{\prime} \mathrm{TG}$ & 11.70 & 11.28 & 12.68 & 180 & 179 & -69 & -63 & -179 & 46 & -67 & -56 \\
\hline $\mathrm{E}_{17}$ & $\mathrm{GTG}^{\prime} \mathrm{TTG}^{\prime}$ & 8.18 & 13.89 & 14.00 & 91 & -178 & -64 & -175 & 162 & -56 & 162 & -73 \\
\hline $\mathrm{E}_{18}$ & $\mathrm{G}^{\prime} \mathrm{TTG}^{\prime} \mathrm{TG}^{\prime}$ & 8.14 & 14.05 & 20.37 & -98 & -177 & 179 & -59 & 176 & -53 & -49 & -58 \\
\hline $\mathrm{E}_{19}$ & TTTTG $^{\prime} \mathrm{G}^{\prime}$ & 16.78 & 14.07 & 13.66 & 180 & -177 & 179 & -176 & -95 & -55 & -54 & 37 \\
\hline $\mathrm{E}_{20}$ & $\mathrm{GTG}^{\prime} \mathrm{G}^{\prime} \mathrm{TG}$ & 10.41 & 15.95 & 12.69 & 90 & -174 & -57 & -67 & -156 & 56 & 86 & 79 \\
\hline $\mathrm{E}_{21}$ & $\mathrm{TGTG}^{\prime} \mathrm{TT}$ & 16.45 & 16.24 & 16.68 & 177 & 88 & 177 & -59 & 179 & 175 & -47 & -56 \\
\hline $\mathrm{E}_{22}$ & TTGTG $^{\prime} \mathrm{G}^{\prime}$ & 18.53 & 17.23 & 21.40 & -180 & 177 & 65 & -178 & -99 & -56 & 51 & 31 \\
\hline $\mathrm{E}_{23}$ & $\mathrm{TTG}^{\prime} \mathrm{GTG}^{\prime}$ & 17.00 & 17.89 & 18.93 & 176 & -179 & -64 & 79 & 172 & -54 & -170 & -61 \\
\hline $\mathrm{E}_{24}$ & $\mathrm{TTG}^{\prime} \mathrm{GTG}^{\prime}$ & 19.27 & 19.77 & 21.29 & 177 & -179 & -67 & 76 & 171 & -53 & -74 & -62 \\
\hline $\mathrm{E}_{25}$ & $\mathrm{G}^{\prime} \mathrm{TGTG}^{\prime} \mathrm{G}$ & 16.94 & 21.06 & 18.32 & -81 & 165 & 67 & -180 & -78 & 41 & 52 & 47 \\
\hline $\mathrm{E}_{26}$ & $\mathrm{TTG}^{\prime} \mathrm{TG}^{\prime} \mathrm{G}^{\prime}$ & 23.78 & 22.07 & 26.68 & -180 & -179 & -63 & -179 & -103 & -56 & 71 & 26 \\
\hline $\mathrm{E}_{27}$ & $\mathrm{TTGG}^{\prime} \mathrm{G}^{\prime} \mathrm{G}$ & 25.74 & 23.17 & 20.34 & -167 & 173 & 74 & -68 & -90 & 46 & 50 & 40 \\
\hline $\mathrm{E}_{28}$ & $\mathrm{G}^{\prime} \mathrm{TGTG}^{\prime} \mathrm{G}^{\prime}$ & 22.78 & 27.70 & 25.61 & -81 & 164 & 67 & -177 & -99 & -56 & 54 & 31 \\
\hline $\mathrm{E}_{29}$ & $\mathrm{GTGTG}^{\prime} \mathrm{G}^{\prime}$ & 24.19 & 28.16 & 27.11 & 95 & 177 & 66 & -177 & -99 & -56 & 51 & 32 \\
\hline $\mathrm{E}_{30}$ & $\mathrm{GTGG}^{\prime} \mathrm{TG}^{\prime}$ & 25.15 & 30.19 & 24.21 & 85 & 178 & 86 & -55 & -172 & -50 & 29 & -47 \\
\hline $\mathrm{E}_{\mathrm{A}}$ & $\mathrm{TGGG}^{\prime} \mathrm{TG}^{\prime}$ & 14.42 & 13.88 & 4.24 & 171 & 93 & 56 & -75 & -164 & -41 & 80 & 71 \\
\hline $\mathrm{E}_{\mathrm{B}}$ & $\mathrm{TGGG}^{\prime} \mathrm{TG}$ & 13.69 & 14.01 & 3.82 & 175 & 90 & 55 & -76 & -159 & 55 & 80 & 74 \\
\hline $\mathrm{E}_{\mathrm{C}}$ & $\mathrm{TG}^{\prime} \mathrm{TG}^{\prime} \mathrm{TG}^{\prime}$ & 13.71 & 16.39 & 15.98 & -158 & -109 & 179 & -61 & 174 & -54 & -50 & -60 \\
\hline $\mathrm{E}_{\mathrm{D}}$ & $\mathrm{GTG}^{\prime} \mathrm{G}^{\prime} \mathrm{TG}$ & 16.62 & 20.13 & 7.24 & 59 & 130 & -56 & -61 & -157 & 56 & 83 & 78 \\
\hline $\mathrm{E}_{\mathrm{E}}$ & TGGGTG $^{\prime}$ & 21.09 & 21.84 & 19.51 & 170 & 98 & 56 & 55 & 155 & -56 & 56 & -81 \\
\hline $\mathrm{E}_{\mathrm{F}}$ & $\mathrm{TG}^{\prime} \mathrm{GG}^{\prime} \mathrm{TG}$ & 28.52 & 22.23 & 0.00 & 173 & -99 & 61 & -75 & -161 & 55 & 89 & 73 \\
\hline $\mathrm{E}_{\mathrm{G}}$ & $\mathrm{TG}^{\prime} \mathrm{G}^{\prime} \mathrm{GTG}^{\prime}$ & 27.65 & 26.00 & 23.24 & -175 & -86 & -59 & 74 & 169 & -53 & 72 & -63 \\
\hline $\mathrm{E}_{\mathrm{H}}$ & $\mathrm{G}^{\prime} \mathrm{G}^{\prime} \mathrm{TG}^{\prime} \mathrm{TT}$ & 26.61 & 28.33 & 21.42 & -67 & -89 & -166 & -58 & 179 & 175 & -53 & -56 \\
\hline $\mathrm{E}_{\mathrm{I}}$ & TGGTG'G & 29.76 & 28.95 & 20.75 & -122 & 100 & 63 & -180 & -79 & 40 & 53 & 45 \\
\hline $\mathrm{E}_{\mathrm{J}}$ & $\mathrm{G}^{\prime} \mathrm{G}^{\prime} \mathrm{GGTG}$ & 36.84 & 32.04 & 11.40 & -48 & -82 & 73 & 56 & 158 & 41 & 44 & -79 \\
\hline $\mathrm{E}_{\mathrm{K}}$ & $\mathrm{TG}^{\prime} \mathrm{G}^{\prime} \mathrm{GTT}$ & 39.20 & 36.93 & 27.28 & 162 & -77 & -56 & 76 & 168 & 173 & 72 & -64 \\
\hline $\mathrm{E}_{\mathrm{L}}$ & $\mathrm{TTGG}^{\prime} \mathrm{TG}^{\prime}$ & 38.91 & 37.24 & 16.47 & 144 & -132 & 83 & -35 & -178 & -46 & 36 & -49 \\
\hline $\mathrm{E}_{\mathrm{M}}$ & TTGG ${ }^{\prime} \mathrm{G}^{\prime} \mathrm{G}$ & 39.40 & 38.83 & 29.25 & -132 & -139 & 71 & -65 & -94 & 40 & 52 & 35 \\
\hline $\mathrm{E}_{\mathrm{N}}$ & $\mathrm{TG}^{\prime} \mathrm{GG}^{\prime} \mathrm{G}^{\prime} \mathrm{G}$ & 41.96 & 38.84 & 28.09 & -154 & -95 & 72 & -66 & -89 & 40 & 52 & 42 \\
\hline $\mathrm{E}_{\mathrm{O}}$ & GGGTG'T $^{\prime}$ & 43.52 & 42.02 & 34.78 & 66 & 88 & 56 & -179 & -99 & 173 & 53 & 31 \\
\hline $\mathrm{E}_{\mathrm{P}}$ & $\mathrm{G}^{\prime} \mathrm{TGG}^{\prime} \mathrm{G}^{\prime} \mathrm{G}^{\prime}$ & 57.95 & 53.06 & 37.50 & -38 & -130 & 81 & -54 & -117 & -46 & 47 & 19 \\
\hline
\end{tabular}

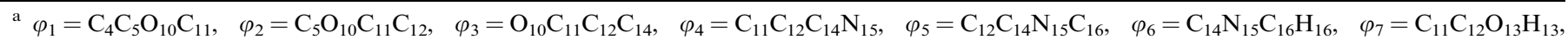
$\varphi_{8}=\mathrm{C}_{12} \mathrm{C}_{14} \mathrm{~N}_{15} \mathrm{H}_{15}$.

${ }^{\mathrm{b}}$ Conformations $\mathrm{E}_{1}$ to $\mathrm{E}_{30}$ were fully optimized at $\mathrm{HF} / 6-31 \mathrm{G}^{*}$ level while conformations $\mathrm{E}_{\mathrm{A}}$ to $\mathrm{E}_{\mathrm{p}}$ were partially optimized at the same level.

The two most stable conformations at the MP2 level, $\mathrm{E}_{\mathrm{F}}$ and $\mathrm{E}_{8}$, are presented in Fig. 2. The conformational arrangement of $E_{8}$ (like $E_{13}$ and $E_{15}$ ) enables the formation of an intramolecular $\mathrm{H}$-bond between the $\mathrm{NH}$ group and the ether oxygen $(\mathrm{NH} \cdots \mathrm{O})$ as well as the $\mathrm{OH} \cdots \mathrm{N}$ bond. In the case of $\mathrm{E}_{\mathrm{F}}$ an additional interaction between the $\mathrm{NH}$ group and the $\pi$ system is also possible. The main difference between the two conformations (see dihedral labels in Table 1), lies in the orientation of $\phi_{2}\left(176^{\circ}\right.$ in $E_{8}$ and $-99^{\circ}$ in $\mathrm{E}_{\mathrm{F}}$ ), which increases the folding of $\mathrm{E}_{\mathrm{F}}$ relatively to $\mathrm{E}_{8}$. It is worth noticing that $\mathrm{E}_{\mathrm{F}}$ converges to $\mathrm{E}_{8}$ after full HF optimization.

Unlike the conformations mentioned above, some other folded ones, displayed in Table 1, present high relative energy values, even at the MP2 level $\left(E_{O}, E_{N}, E_{I}, E_{H}, E_{P}\right.$, $\mathrm{E}_{\mathrm{K}}$, and $\mathrm{E}_{\mathrm{M}}$ ). In such cases, the stabilization due to disper- 

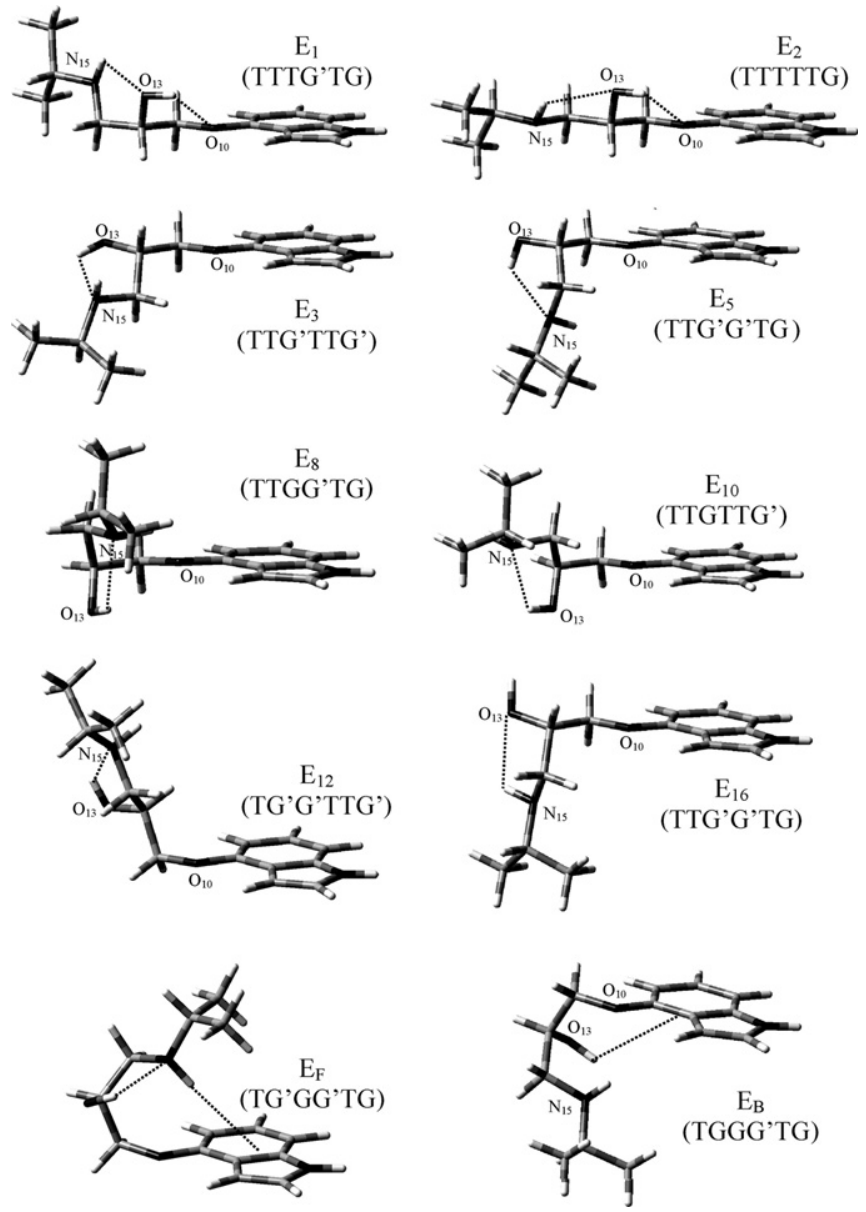

Fig. 2. Optimized geometries $\left(\mathrm{HF} / 6-31 \mathrm{G}^{*}\right)$ of some conformations of pindolol in the gas phase illustrating different types of backbone arrangements and intramolecular $\mathrm{H}$-bonds. $\mathrm{E}_{1}$ to $\mathrm{E}_{16}$ correspond to fully optimized structures; $\mathrm{E}_{\mathrm{B}}$ and $\mathrm{E}_{\mathrm{F}}$ were partially optimized.

sion interactions is overcome by unfavourable configurations resulting from the deviation of $\varphi_{1}, \varphi_{2}, \varphi_{5}$ and $\varphi_{6}$ from their preferred orientations.

The particular role played by the $\varphi_{1}$ and $\varphi_{2}$ torsional angles in the characterization of the backbone structure of pindolol deserves a detailed study, namely by mapping the potential energy profile around these two coordinates. As these two dihedrals do not seem to be particularly dependent on the calculation method used and since HF and DFT are computationally less expensive than MP2, this study was undertaken using the former methods. Taking $E_{1}$ as the starting structure, successive rotations about $\varphi_{1}$ using a $30^{\circ}$ scanning step were performed. At each point all the remaining structural parameters were optimized at the $\mathrm{HF} / 6-31 \mathrm{G}^{*}$ level of theory followed by a B3LYP/6$311++\mathrm{G}^{* *}$ energy calculation. The resulting potential energy profile is depicted in Fig. 3. The minimum energy occurs at $\varphi_{1} \approx 180^{\circ}$. Two other minima at $\varphi_{1}=90^{\circ}$ and $\varphi_{1}=$ $-90^{\circ}$ with energies of $c a .12 \mathrm{~kJ} \mathrm{~mol}^{-1}$ above the first were also observed. As $\varphi_{1}$ approaches $0^{\circ}$ the energy increases due to the repulsive interaction between the side chain of the molecule and the pyrrol aromatic ring moiety.

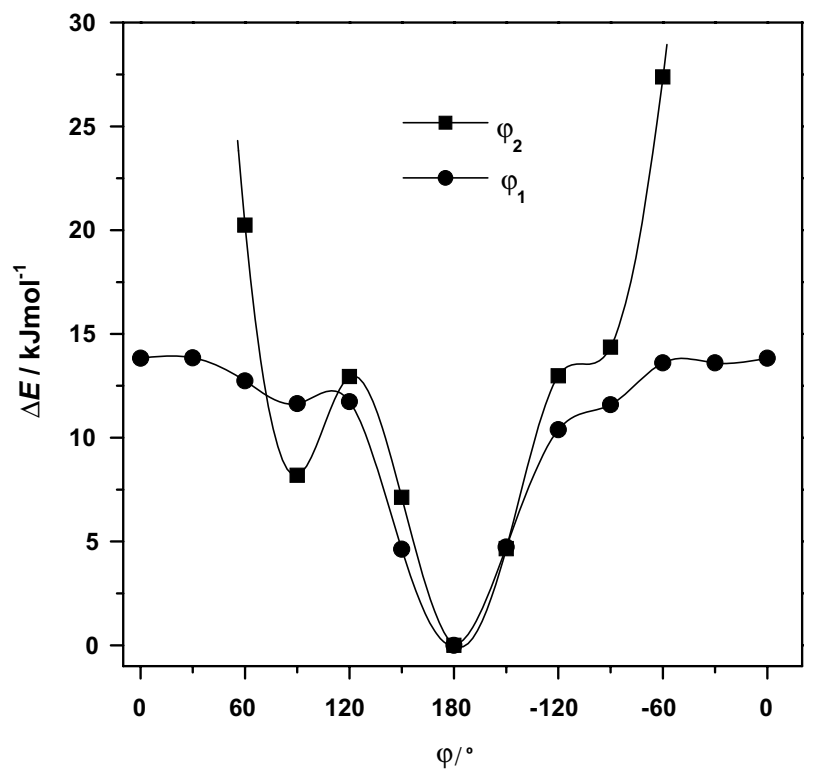

Fig. 3. Potential energy profile as a function of $\varphi_{1}$ and $\varphi_{2}$ (with $\varphi_{1}$ fixed at $180^{\circ}$ ) using a $30^{\circ}$ scanning step. $E_{1}$ was used as starting structure in both scans. At each point all the remaining internal coordinates were relaxed at the $\mathrm{HF} / 6-31 \mathrm{G}^{*}$ level of theory followed by $\mathrm{B} 3 \mathrm{LYP} / 6-311++\mathrm{G}^{* *}$ singlepoint calculation.

Following an identical methodology the potential energy profile around $\varphi_{2}$ with $\varphi_{1}$ fixed at $180^{\circ}$ was obtained and is represented in Fig. 3. The potential energy pattern is akin to that around $\varphi_{1}$ with the lowest minimum energy occurring at $\varphi_{2}=180^{\circ}$ and two higher energy minima at $\varphi_{2}=90^{\circ}$ and $-90^{\circ}$ of $c a .8$ and $14 \mathrm{~kJ} \mathrm{~mol}^{-1}$, respectively, above the lowest energy minimum. For $\varphi_{2}<90^{\circ}$ or $\varphi_{2}<-90^{\circ}$ the side chain rotation is hindered by the benzenoid ring moiety.

As it was already mentioned above, we are not aware of any experimental or theoretical study performed on pindolol in the gas phase to be compared with our results. The only structural data about this compound available in literature are referred to its crystalline structure $[5,6]$. It is interesting to note that the conformation of pindolol exhibited in the crystal is very close to $E_{2}$, the second most stable conformer predicted by our DFT theoretical calculations.

\subsection{Geometric parameters related to intramolecular hydrogen bonding}

As it has been mentioned before, a structural feature accounting to the definition of the minima on the potential energy surface of pindolol is the establishment of hydrogen bonds between the polar groups. The hydroxyl and amine groups are able to act both as hydrogen donors (D) or acceptors (A) whereas the ether oxygen is only acceptor. In what follows, a detailed discussion concerning H-bonding for the sixteen lowest energy conformers at the DFT and MP2 levels is undertaken, as they account for all the different types of $\mathrm{H}$-bonds in the HF fully optimized struc- 
tures. The $\mathrm{NH} \cdots \pi$ and $\mathrm{OH} \cdots \pi$ interactions cannot be included in this discussion since they are not present in the fully optimized structures and mostly because the $\mathrm{H} \cdots \pi$ distance, the most important parameter to be used in the discussion of this type of interactions, either from the viewpoint of geometrical considerations or from the analysis of the vibrational frequencies, corresponds to a non-optimized parameter at the HF level of theory.

On structural grounds, H-bonding is evidenced by short $\mathrm{H} \cdot \mathrm{AA}$ distances and favourable D-H..A angles. Distances up to 3.0-3.2 $\AA$ should be accepted as a manifestation of an H-bond [27]. The directional and soft characteristics of the $\mathrm{H}$-bond interaction lead to values close to linearity for the preferred orientation, but still present for D-H. A A angles $>110^{\circ}$ or even smaller [28]. We must recognize that cut-off values of the $\mathrm{H}$-bond are conventional, since no definite separation exists between the $\mathrm{H}$-bond and the van der Waals interactions $[29,30]$. As H-bonding depends on the $\mathrm{H} \cdots \mathrm{A}$ distance and D-H $\cdots$ A angle, a plot of these parameters can give an elucidative view of this type of interaction in pindolol. This representation is found in Fig. 4.

All conformers exhibit geometrical parameters acceptable for the formation of intramolecular H-bonds. In Table 2 are presented the conformers with only one H-bond and the combination of dihedral orientations leading to favourable positions of the donor and acceptor groups. While some pindolol conformers present only one of the H-bond types described in Table 2, some of the others exhibit simultaneously two of these (e.g., $\mathrm{E}_{1}, \mathrm{E}_{2}$ and $\mathrm{E}_{6}$ ) and in a few cases the occurrence of $\mathrm{O}_{13}-\mathrm{H}_{13} \cdots \mathrm{N}_{15}$ results from a structure favouring the $\mathrm{N}_{15}-\mathrm{H}_{15} \cdots \mathrm{O}_{10}$ interaction (e.g., $\mathrm{E}_{8}, \mathrm{E}_{13}$ and $\mathrm{E}_{15}$ ).

Several bond sets are evidenced in Fig. 4. Eight conformers with D-H.AA angles ranging from 108 to $101^{\circ}$ and $\mathrm{H} \cdots \mathrm{A}$ distances varying between 2.25 and $2.48 \AA$ exhibit individually or simultaneously $\mathrm{O}_{13}-\mathrm{H}_{13} \cdots \mathrm{O}_{10}$ or $\mathrm{N}_{15}-\mathrm{H}_{15} \cdots \mathrm{O}_{13}$ bonds. As the geometric parameters are very close to the cutoff limits, these should be classified

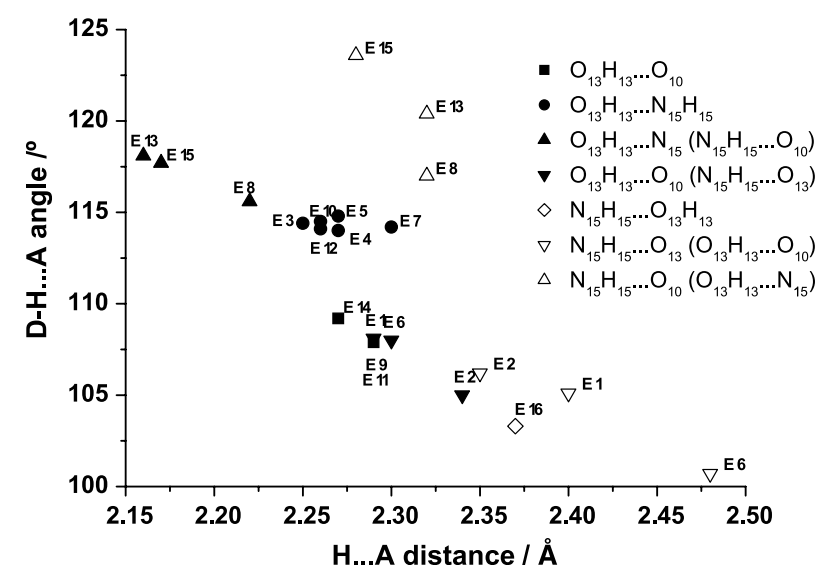

Fig. 4. Hydrogen bond angle vs. distance for conformers $E_{1}$ to $E_{16}$. The $\mathrm{H}$-bonds accompanying that one under consideration are indicated in parentheses.
Table 2

Intramolecular hydrogen bonds exhibited in pindolol and dihedral angle orientations leading to their formation

\begin{tabular}{lll}
\hline $\mathrm{H}$-bond & Dihedral orientations & Conformers $^{\mathrm{a}}$ \\
\hline $\mathrm{O}_{13} \mathrm{H}_{13} \cdots \mathrm{O}_{10}$ & $\left(\varphi_{3} \mathrm{~T}\right.$ and $\left.\varphi_{7} \mathrm{G}^{\prime}\right)$ or & $\mathrm{E}_{9}, \mathrm{E}_{11}, \mathrm{E}_{14}$ \\
& $\left(\varphi_{3} \mathrm{G}\right.$ and $\left.\varphi_{7} \mathrm{G}\right)$ & \\
$\mathrm{O}_{13} \mathrm{H}_{13} \cdots \mathrm{N}_{15}$ & $\left(\varphi_{4} \mathrm{~T}\right.$ and $\left.\varphi_{7} \mathrm{~T}\right)$ or & $\mathrm{E}_{3}, \mathrm{E}_{4}, \mathrm{E}_{5}, \mathrm{E}_{7}, \mathrm{E}_{10}, \mathrm{E}_{12}$ \\
& $\left(\varphi_{4} \mathrm{G}^{\prime}\right.$ and $\left.\varphi_{7} \mathrm{G}\right)$ & \\
$\mathrm{N}_{15} \mathrm{H}_{15} \cdots \mathrm{O}_{13}$ & $\varphi_{4} \mathrm{G}^{\prime}, \varphi_{7} \mathrm{G}^{\prime}, \varphi_{8} \mathrm{G}^{\prime}$ & $\mathrm{E}_{16}$ \\
\hline${ }^{a}$ Conformers presenting only the considered H-bond.
\end{tabular}

as weak $\mathrm{H}$-bonds. Between these two bonds, $\mathrm{O}_{13^{-}}$ $\mathrm{H}_{13} \cdots \mathrm{O}_{10}$ is favoured over $\mathrm{N}_{15}-\mathrm{H}_{15} \cdots \mathrm{O}_{13}$ and a variability of strength is expected for each of them, as can be confirmed by the diversity of angles and distances.

The $\mathrm{O}_{13}-\mathrm{H}_{13} \cdots \mathrm{N}_{15}$ bond is found together with $\mathrm{N}_{15}$ $\mathrm{H}_{15} \cdots \mathrm{O}_{10}\left(\mathrm{E}_{8}, \mathrm{E}_{13}\right.$ and $\left.\mathrm{E}_{15}\right)$ or alone $\left(\mathrm{E}_{3}, \mathrm{E}_{4}, \mathrm{E}_{5}, \mathrm{E}_{7}, \mathrm{E}_{10}\right.$ and $\left.\mathrm{E}_{12}\right)$ in a range of $\mathrm{H}$-bond angles from 118 to $113^{\circ}$ and in distances from 2.16 to $2.32 \AA$. An almost linear decrease of the angles with the increase of distance is observed. The H-bond parameters are more favourable when both bonds coexist than when the first is the only one present, as would be expected from the H-bond cooperativity effect $[27,31,32]$. Although differences between the conformers are expected owing to their structural features, this H-bond is stronger than those considered in the previous group of conformers.

Finally, the $\mathrm{N}_{15}-\mathrm{H}_{15} \cdots \mathrm{O}_{10}$ that accompanies the $\mathrm{O}_{13}$ $\mathrm{H}_{13} \cdots \mathrm{N}_{15}$ in the conformers $\mathrm{E}_{8}, \mathrm{E}_{13}$ and $\mathrm{E}_{15}$ gives rise to stronger $\mathrm{H}$-bonds in pindolol attending to the favoured donor-acceptor orientation and relatively short distances, these conformations being particularly stabilized at the MP2 level.

Two important conclusions are taken from the data given above on H-bonding in pindolol: all the conformers present, at least, one $\mathrm{H}$-bond in a relative wide strength range and no correlation can be established between the $\mathrm{H}$-bonding parameters and the electronic energy of the conformers. This means that this interaction is not the dominant factor in the energy ordering of the different conformers of pindolol.

\subsection{H-bonding manifestation from calculated vibrational spectra}

Infrared spectroscopy is a privileged method to supply details on H-bonding. This particularity is explored now to complement the data obtained on the structure parameter grounds. For these purposes, the vibrational frequencies of the fully HF optimized conformers were calculated.

One of the spectroscopic features relating H-bond with vibration modes is the stretching frequency shift defined by

$\Delta \bar{v}=\bar{v}_{\mathrm{D}-\mathrm{H} \cdots \mathrm{A}}-\bar{v}_{\mathrm{D}-\mathrm{H}}$

where $\bar{v}_{\mathrm{D}-H}$ and $\bar{v}_{\mathrm{D}-\mathrm{H} \cdots \mathrm{A}}$ are the wavenumber band maximum for the free group and for the group involved in the 


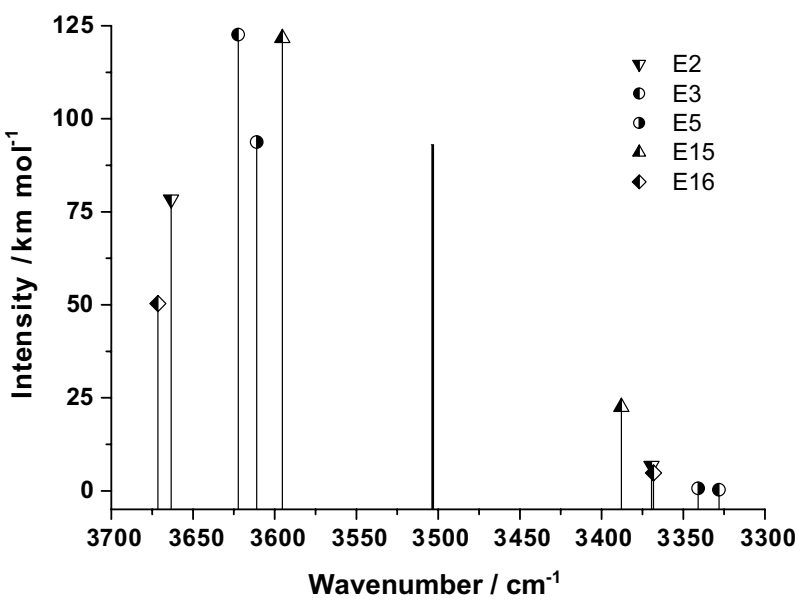

Fig. 5. Calculated spectra $\left(\mathrm{HF} / 6-31 \mathrm{G}^{*}\right)$ of some conformers of pindolol in the $\mathrm{OH}$ and $\mathrm{NH}$ stretching regions. The line at $c a .3500 \mathrm{~cm}^{-1}$ is assigned to the indole $\mathrm{NH}$ group. The lines to the right correspond to the amine $\mathrm{NH}$ and the ones to the left to $\mathrm{OH}$.

H-bond, respectively. The $\bar{v}$ shift is normally more pronounced for the stretching vibration modes.

Fig. 5 presents typical spectra of some pindolol conformers in the $3700-3200 \mathrm{~cm}^{-1}$ region. The wavenumbers were scaled by a factor of 0.8929 [33]. In this frequency range, the $\mathrm{O}_{13}-\mathrm{H}_{13}, \mathrm{~N}_{1}-\mathrm{H}_{1}$ and $\mathrm{N}_{15}-\mathrm{H}_{15}$ stretching vibration modes are observed. While $\bar{v}\left(\mathrm{~N}_{1}-\mathrm{H}_{1}\right)$ appears at $c a$. $3500 \mathrm{~cm}^{-1}$ for all conformers, variation from one conformer to another occurs for the two other groups. The stretching vibration of the $\mathrm{NH}$ secondary amine is vanishingly weak. However, when this group acts as a donor in an $\mathrm{H}$-bond formation, in addition to the stretching frequency displacement, the intensity increases.

The stretching vibration frequencies of the $\mathrm{O}_{13} \mathrm{H}_{13}$ and $\mathrm{N}_{15} \mathrm{H}_{15}$ free groups are calculated as 3671 and $3328 \mathrm{~cm}^{-1}$, obtained from $\mathrm{E}_{16}$ and $\mathrm{E}_{3}$, respectively. In Table 3, the values of $\Delta \bar{v}$ found for $\mathrm{O}_{13} \mathrm{H}_{13}$ and $\mathrm{N}_{15} \mathrm{H}_{15}$

Table 3

Stretching vibration wavenumber shifts of $\mathrm{O}_{13} \mathrm{H}_{13}$ and $\mathrm{N}_{15} \mathrm{H}_{15}$

\begin{tabular}{lll}
\hline Conformer & $\Delta \bar{v} / \mathrm{cm}^{-1}$ & \\
\cline { 2 - 3 } & $\mathrm{O}_{13}-\mathrm{H}_{13}$ & $\mathrm{~N}_{15}-\mathrm{H}_{15}$ \\
\hline $\mathrm{E}_{1}$ & -15.8 & 34.4 \\
$\mathrm{E}_{2}$ & -10.5 & 39.8 \\
$\mathrm{E}_{3}$ & -51.5 & - \\
$\mathrm{E}_{4}$ & -47.0 & 10.2 \\
$\mathrm{E}_{5}$ & -62.8 & 11.3 \\
$\mathrm{E}_{6}$ & -15.6 & 25.9 \\
$\mathrm{E}_{7}$ & -58.9 & 27.5 \\
$\mathrm{E}_{8}$ & -59.5 & 50.4 \\
$\mathrm{E}_{9}$ & -13.2 & 11.8 \\
$\mathrm{E}_{10}$ & -49.3 & - \\
$\mathrm{E}_{11}$ & -12.7 & - \\
$\mathrm{E}_{12}$ & -52.2 & - \\
$\mathrm{E}_{13}$ & -85.4 & 44.7 \\
$\mathrm{E}_{14}$ & -21.5 & - \\
$\mathrm{E}_{15}$ & -78.5 & 58.3 \\
$\mathrm{E}_{16}$ & - & 38.7 \\
\hline
\end{tabular}

in the sixteen conformers of pindolol, are reported. This table shows that most of the sixteen conformers present displacements of the stretching vibration of $\mathrm{O}_{13}-\mathrm{H}_{13}$ and $\mathrm{N}_{15}-\mathrm{H}_{15}$. However, while the former group originates red shifts, the latter gives rise to blue shifts. From a simplistic model, a red shift would be the expected effect as far as the $\mathrm{D}-\mathrm{H} \cdots \mathrm{A}$ interaction increases the $\mathrm{D}-\mathrm{H}$ bond length. Blue shift has been described in $\mathrm{C}-\mathrm{H} \cdots \mathrm{O}, \mathrm{C}-\mathrm{H} \cdots \pi$ and $\mathrm{N}-$ $\mathrm{H} \cdots \mathrm{O}$ systems [34-36]. The explanations advanced for the blue shift effect were reviewed by Alabugin et al. [37]. These authors outlined a model in which the H-bonding stabilization results from the transfer of electron lone pairs of the acceptor to an antibonding $\mathrm{D}-\mathrm{H}$ orbital (hyperconjugative $n(\mathrm{~A}) \rightarrow \sigma^{*}(\mathrm{D}-\mathrm{H})$ interaction) and also from the increase of s-character and polarization of $\mathrm{D}-\mathrm{H}$ bond. The former decreases the bond order while the latter produces the opposite effect. The direction of the wavenumber shift depends on the balancing of both effects.

Although $\Delta \bar{v}$ is bond strength dependent and some expressions have been worked out to relate $\Delta \bar{v}$ with the interaction enthalpy for intermolecular H-bonding [38], it is not safe to use these expressions for red and blue shifts in intramolecular $\mathrm{H}$-bonds. The strength of the H-bonds is therefore expressed in $\Delta \bar{v}$ values.

The values tabled for $\Delta \bar{v}$ show that most of the pindolol conformers exhibit $\mathrm{H}$-bonds. The $\mathrm{O}_{13}-\mathrm{H}_{13} \cdots \mathrm{N}_{15}$ and $\mathrm{N}_{15^{-}}$ $\mathrm{H}_{15} \cdots \mathrm{O}_{10}$ are the main specific interactions of the H-bonding network of pindolol. These two H-bonds coexist in some conformers. The $\Delta \bar{v}$ values observed for $\mathrm{N}_{15^{-}}$ $\mathrm{H}_{15} \cdots \mathrm{O}_{13}$ are not far below those found for $\mathrm{N}_{15^{-}}$ $\mathrm{H}_{15} \cdots \mathrm{O}_{10}$ and that interaction is present in several conformers together with $\mathrm{O}_{13}-\mathrm{H}_{13} \cdots \mathrm{O}_{10}\left(\mathrm{E}_{1}, \mathrm{E}_{2}, \mathrm{E}_{6}\right)$ or alone as in $\mathrm{E}_{16}$. On the grounds of the $\Delta \bar{v}$ values, the last H-bond is a very weak one.

The general view on $\mathrm{H}$-bonding supplied by Table 3 is in accordance with the D-H.AA angles and $\mathrm{H} \cdots \mathrm{A}$ distances displayed in Fig. 4. However, it should be pointed out that the spectroscopic manifestations of the H-bonds give more quantitative and clear indications on these interactions than the geometric parameters. Bearing this in mind, it is worth to note the different dependence on these parameters observed for the most important H-bond systems of pindolol. Plotting $\Delta \bar{v}$ against $\mathrm{D}-\mathrm{H} \cdots \mathrm{A}$ angle or $\mathrm{H} \cdots \mathrm{A}$ distance (data provided as Supplementary material) allows to conclude that while $\mathrm{O}_{13}-\mathrm{H}_{13} \cdots \mathrm{N}_{15}$ is strongly dependent on donor-acceptor orientation, the $\mathrm{N}_{15}-\mathrm{H}_{15} \cdots \mathrm{O}_{10}$ is less dependent on the orientation but strongly dependent on $\mathrm{H}$...A distance. This different behaviour derives from the different nature of the bonds as referred above.

\section{Concluding remarks}

The structure of the isolated pindolol molecule was determined at the HF/6-31G* level of theory and the corresponding energy calculated at the B3LYP/6-311++G(d,p) and MP2/6-311++G(d,p) levels. The structures of the most significant conformers were reported as well as their 
respective values of the electronic energy at the different electronic structure methods employed.

According to the energy ordering of the conformers, it can be concluded from our results that while DFT method favours more extended structures, MP2 stabilizes some of the more folded ones. However, most of the lower energy conformations predicted by HF and DFT have also a significant weight in the conformational distribution at the MP2 level. From the combination of the results obtained from the different methods, the most significant structural features of pindolol were identified and discussed.

Intramolecular $\mathrm{H}$-bonds, although not the energetically dominant structural feature, play a key role in the structural stabilization of most of pindolol conformers that were studied, either on the grounds of geometric parameters or from the stretching vibration shifts of $\mathrm{O}-\mathrm{H}$ and $\mathrm{N}-\mathrm{H}$ bonds.

\section{Acknowledgements}

A.J. Lopes Jesus and Sandra C.C. Nunes acknowledge Fundação para a Ciência e a Tecnologia (FCT), Lisbon, for financial support. Grants SFRH/BD/9110/2002 and SFRH/BD/1902/2004, respectively.

\section{Appendix A. Supplementary data}

Supplementary data associated with this article can be found, in the online version, at doi:10.1016/ j.theochem.2006.11.029.

\section{References}

[1] G. Bachour, H. Losse, F. Bender, F. Wessels, Med. Klin. 71 (1976) 580.

[2] J. Holmboe, P. Lilleåsen, E. Normann, Acta Anaesthesiol. Scand. 20 (1976) 70.

[3] J.H. Atterhog, H. Duner, B. Pernow, Am. J. Med. 60 (1976) 872.

[4] S.C.C. Nunes, M.E.S. Eusébio, M.L.P. Leitão, J.S. Redinha, Int. J. Pharm. 285 (2004) 13.

[5] M. Gadret, M. Goursolle, J.M. Leger, J.C. Colleter, Acta Crystallogr. Sect. B 32 (1976) 17.
[6] T.K. Chattopadhyay, R.A. Palmer, D. Mahadevan, J. Chem. Crystallogr. 25 (1995) 195.

[7] M.J.S. Dewar, E.G. Zoebisch, E.F. Healy, J.J.P. Stewart, J. Am. Chem. Soc. 107 (1985) 3902.

[8] M.J. Hwang, T.P. Stockfisch, A.T. Hagler, J. Am. Chem. Soc. 116 (1994) 2515.

[9] J.R. Maple, U. Dinur, A.T. Hagler, Proc. Natl. Acad. Sci. USA 85 (1988) 5350.

[10] Hyperchem 7.5 for windows (Evaluation version), Hypercube Inc.

[11] J.M. Bakker, C. Plutzer, I. Hunig, T. Haber, I. Compagnon, G. von Helden, G. Meijer, K. Kleinermanns, Chem. Phys. Chem. 6 (2005) 120 .

[12] I. Hunig, K. Kleinermanns, Phys. Chem. Chem. Phys. 6 (2004) 2650.

[13] D. Toroz, T. Van Mourik, Mol. Phys. 104 (2006) 559.

[14] H. Valdes, D. Reha, P. Hobza, J. Phys. Chem. B 110 (2006) 6385.

[15] J.P. James, J. Stewart, Comput. Chem. 10 (1989) 209.

[16] J.P. James, J. Stewart, Comput. Chem. 10 (1989) 221.

[17] P. Hohenberg, W. Kohn, Phys. Rev. B 136 (1964) B864.

[18] W. Kohn, L.J. Sham, Phys. Rev. 140 (1965) 1133.

[19] A.D. Becke, Phys. Rev. A 38 (1988) 3098.

[20] A.D. Becke, J. Chem. Phys. 98 (1993) 5648.

[21] C.T. Lee, W.T. Yang, R.G. Parr, Phys. Rev. B 37 (1988) 785.

[22] M.J. Frisch, M. Head-Gordon, J.A. Pople, Chem. Phys. Lett. 166 (1990) 275.

[23] M.J. Frisch, M. Head-Gordon, J.A. Pople, Chem. Phys. Lett. 166 (1990) 281.

[24] M.J. Frisch, et al., Gaussian 98, revision A.9, Gaussian, Inc, Pittsburgh, PA, 1998.

[25] N.A. Macleod, J.P. Simons, Chem. Phys. 283 (2002) 221.

[26] T. van Mourik, P.G. Karamertzanis, S.L. Price, J. Phys. Chem. A 110 (2006) 8.

[27] G.A. Jeffrey, An Introduction to Hydrogen Bonding, Oxford University Press, Oxford, 1997.

[28] T. Steiner, Angew. Chem.-Int. Edit. 41 (2002) 48.

[29] T. Steiner, G.R. Desiraju, Chem. Commun. (1998) 891.

[30] N.N.L. Madhavi, G.R. Desiraju, A.K. Katz, H.L. Carrell, A. Nangia, Chem. Commun. (1997) 1953.

[31] M.L. Paz, G. Ellis, M. Pérez, J. Perkins, J. Jiménez-Barbero, C. Vicent, Eur. J. Org. Chem. 2002 (2002) 840.

[32] J.L. Dashnau, K.A. Sharp, J.M. Vanderkooi, J. Phys. Chem. B 109 (2005) 24152.

[33] A.P. Scott, L. Radom, J. Phys. Chem. 100 (1996) 16502.

[34] H. Matsuura, H. Yoshida, M. Hieda, S.-y. Yamanaka, T. Harada, K. Shin-ya, K. Ohno, J. Am. Chem. Soc. 125 (2003) 13910.

[35] P. Hobza, Z. Havlas, Chem. Phys. Lett. 303 (1999) 447.

[36] H.M. Muchall, J. Phys. Chem. A 105 (2001) 632.

[37] I.V. Alabugin, M. Manoharan, S. Peabody, F. Weinhold, J. Am. Chem. Soc. 125 (2003) 5973.

[38] A.V. Iogansen, Spectrochim. Acta, Part A 55 (1999) 1585. 